\title{
Pembentukan kader kesehatan jiwa sekolah dan pelatihan penanganan masalah psikososial di SD N Krapyak Semarang \\ Establishment of School Health Care and Training of Psychosial Problem Services in SDN Krapyak Semarang
}

\author{
Mariyati", Khusnul Aini, Nana Rohana \\ Program Studi Ners STIKes Widya Husada Semarang, Indonesia \\ *Corresponding Authour \\ Email: maryhamasah@gmail.com \\ $\begin{array}{llll}\text { Received: } & \text { Revised: } & \text { Accepted: } & \text { Published: } \\ 23 \text { August 2019 } & \text { 4 May 2020 } & \text { 17 May 2020 } & \text { 31 May 2020 }\end{array}$
}

\begin{abstract}
Abstrak
Masalah psikososial pada anak di sekolah mengalami peningkatan. Salah satunya adalah Sekolah Dasar Negeri (SD N) Krapyak Kota Semarang. Penyebab munculnya masalah psikososial di sekolah tersebut diantaranya kecanduan teknologi seperti gadget, kekerasan seperti bullying, tantangan pembelajaran, dan gangguan perilaku (membolos, mencontek dan tidak disiplin). Sesuai permasalahan yang dihadapi SD N Krapyak Kota Semarang maka pentingnya pembentukan kader kesehatan jiwa di sekolah. Program Pengabdian Kepada Masyarakat (PKM) pembentukan kader kesehatan jiwa bertujuan untuk mendeteksi masalah psikososial siswa secara dini, mengatasi masalah psikososial yang terjadi pada siswa, dan merujuk masalah psikososial siswa yang membutuhkan penanganan lebih lanjut. Kegiatan dalam program PKM bekerjasama dengan Usaha Kesehatan Sekolah (UKS). Kegiatan dalam Program PKM ini antara lain: 1) membentuk kader kesehatan jiwa di Sekolah, 2) menjelaskan masalah- masalah psikososial yang sering terjadi pada siswa, 3) mengajarkan cara mengatasi masalah psikososial yang terjadi pada siswa, dan 4) melatih cara merujuk siswa yang memiliki masalah psikososial yang kompleks 5) monitoring dan evaluasi program. Hasil dalam kegiatan- kegiatan tersebut adalah terdapat 15 siswa dan 10 guru sebagai kader kesehatan jiwa di sekolah, hasil deteksi dini didapatkan beberapa masalah psikososial di sekolah yaitu kecemasan, gangguan citra tubuh, harga diri rendah situasional, keputusasaan, dan koping tidak efektif. Selanjutnya, kader kesehatan sekolah melakukan penanganan dengan pendampingan. Kegiatan monitoring dan evaluasi juga dilakukan untuk memastikan kader kesehatan jiwa di sekolah berjalan dengan baik.
\end{abstract}

Kata Kunci: kesehatan jiwa; psikososial; sekolah 


\begin{abstract}
Psychosocial problems in children at school have increased. One of them is Krapyak State Elementary School (SD N) Semarang City. The causes of the emergence of psychosocial problems in the school include technological addictions such as gadgets, violence such as bullying, learning challenges, and behavioral disorders (ditching, cheating and undisciplined). The Community Service Program (PKM) for forming mental health cadres aims to detect students 'psychosocial problems early, overcome psychosocial problems that occur in students, and refer to students' psychosocial problems that require further treatment. Activities in the PKM program in collaboration with the School Health Efforts (UKS). Activities in the PKM Program include: 1) forming mental health cadres in schools, 2) explaining psychosocial problems that often occur to students, 3) teaching how to overcome psychosocial problems that occur in students, and 4) training how to refer students who have complex psychosocial problems 5) program monitoring and evaluation. The results of these activities are that there are 15 students and 10 teachers as mental health cadres in schools, the results of early detection found several psychosocial problems in schools namely anxiety, body image disturbances, low situational self-esteem, hopelessness, and ineffective coping. Furthermore, school health cadres handle with assistance. Monitoring and evaluation activities are also carried out to ensure mental health cadres in schools run well.
\end{abstract}

Keywords: mental health; psychosocial; school

\title{
PENDAHULUAN
}

Community Mental Health Nursing (CMHN) menjelaskan perkembangan psikososial mempunyai delapan tahap perkembangan: bayi, kanak - kanak, pra sekolah, usia sekolah, remaja, dewasa muda, dewasa dan lanjut usia. Jumlah anak sekolah pada tahaun 2018 di Indonesia yaitu 25,5 juta (BPS, 2018). Proses perkembangan yang optimal akan tercapai bila individu diberikan stimulasi tertentu yang akan merangsang perkembangan kemampuan psikososial. Ketidakseimbangan psikologis terjadi bila seseorang tidak dapat beradaptasi terhadap tuntutan secara internal maupun eksternal untuk mencapai tugas perkembangan tertentu sesuai tahapan usia termaksud juga pada usia sekolah. Dapat diartikan bahwa kegagalan tugas perkembangan tahap sebelumnya akan mempengaruhi kemampuan individu menyelesaikan tugas perkembangan tahap berikutnya (Keliat, 2015).

Perkembangan anak usia sekolah (6-12 tahun) mengalami berbagai peningkatan pada aspek kognitif dan psikososial (Yusuf, AH, 2014). Perkembangan kognitif, pada periode ini adalah pikiran anak berkembang secara berangsur-angsur. Jika pada periode sebelumnya, daya pikir anak masih suka mengkhayal atau berfantasi dan berfokus pada diri sendiri (egosentris), maka pada periode ini daya pikir anak sudah berkembang ke arah yang lebih nyata, rasional dan objektif. Daya ingatnya menjadi sangat kuat, sehingga anak benar-benar berada pada tahapan belajar. Dalam upaya memahami alam sekitarnya, mereka tidak lagi terlalu mengandalkan informasi yang bersumber dari pancaindera, karena ia mulai mempunyai kemampuan untuk membedakan apa yang tampak oleh mata dengan kenyataan sesungguhnya (Keliat, 2015). 
Perkembangan psikosial pada tahap ini, anak dapat menghadapi dan menyelesaikan tugas atau perbuatan yangdapat membuahkan hasil, sehingga dunia psikosial anak menjadi semakin kompleks. Anak sudah siap untuk meninggalkan rumah dan orang tuanya dalam waktu terbatas, yaitu pada saat anak berada di sekolah (Yusuf $\mathrm{AH}, 2014)$. Melalui proses pendidikan ini, anak belajar untuk bersaing (kompetitif), kooperatif dengan orang lain, saling memberi dan menerima,setia kawan dan belajar peraturan. Dalam hal ini proses sosialisasi banyak terpengaruh oleh guru dan teman sebaya. Identifikasi bukan lagi terhadap orang tua, melainkan terhadap guru. Selain itu, anak telah mempunyai jiwa kompetitif sehingga dapat memilah apa yang baik bagi dirinya, mampu memecahkan masalahnya sendiri dan mulai melakukan identifikasi terhadap tokoh tertentu yang menarik perhatiannya (Keliat, dkk, 2019).

Perkembangan yang terjadi pada usia sekolah membutuhkan stimulasi agar tidak terjadi berbagai penyimpangan yang marak saat ini. Bullying, membolos, mencuri dan kekerasan merupakan bentuk-bentuk kekerasan yang terjadi saat ini. Bullying berasal dari kata Bully, yaitu suatu kata yang mengacu pada pengertian adanya "ancaman" yang dilakukan seseorang terhadap orang lain (yang umumnya lebih lemah atau "rendah" dari pelaku), yang menimbulkan gangguan psikis bagi korbannya (korban disebut bully boy atau bully girl) berupa stres (yang muncul dalam bentuk gangguan fisik atau psikis, atau keduanya; misalnya susah makan, sakit fisik, ketakutan, rendah diri, depresi, cemas, dan lainnya) (Wardani, Mariyati, \& Tamrin, 2020). Maka untuk menghindari dan mengatasi dampak penyimpangan tersebut diperlukan suatu wadah agar dapat mewujudkan sumberdaya yang tidak hanya sehat secara fisik saja tetapi juga mental dan sosial serta mempunyai produktivitas yang optimal melalui upaya pemeliharaan dan peningkatan kesehatan jiwa yang terus menerus melalui pembinaan dan pengembangan usaha kesehatan jiwa sekolah.

SDN Krapyak Kota Semarang sudah memiliki UKS dengan 15 siswa sebagai pengurus yang sudah pernah dilatih tentang manajemen UKS. Hasil pengamatan dan wawancara di kelas 4 dan 5 beberapa anak menjadi pelaku bullying dan korban bullling, membolos, dan berkelahi. Dalam mewujudkan visi dan misi SDN Krapyak salah satunya adalah melalui pembentukan kader kesehatan jiwa sekolah. Kesehatan jiwa sekolah merupakan bagian dari usaha kesehatan yaitu segala usaha yang dilakukan untuk meningkatkan kesehatan jiwa anak usia sekolah dengan tujuan meningkatkan kemampuan hidup sehat dan derajat kesehatan jiwa anak usia sekolah sedini mungkin. Usaha kesehatan jiwa sekolah dilakukan oleh semua orang yang berperan di dalam proses belajar mengajar termaksud masyarakat yang berada di lingkungan sekolah selain warga sekolah. Berdasarkan hasil pra survei yang telah dilakukan maka permasalahan yang dialami oleh mitra adalah:

a. Aspek pengetahuan tentang penyebab dan macam- macam masalah psikososial pada siswa masih kurang

b. Belum adanya kemampuan dalam melakukan deteksi dini masalah psikososial pada siswa

c. Belum memahami cara penanganan masalah psikososial pada siswa

d. Ketidaktahuan dalam merujuk masalah psikososial siswa yang perlu penanganan lebih lanjut. 


\section{METODE}

Materi dan metode yang telah dilakukan selama kegiatan PKM ini adalah sebagai berikut:

Tabel 1. Materi dan Metode Kegiatan PKM

\begin{tabular}{|c|c|c|c|}
\hline No & Hari/Tanggal & Materi & Metode \\
\hline 1. & 22 Mei 2019 & $\begin{array}{l}\text { 1. Konsep Kader Kesehatan Jiwa } \\
\text { Sekolah } \\
\text { 2. Konsep masalah psikososial }\end{array}$ & $\begin{array}{l}\text { Ceramah } \\
\text { Diskusi }\end{array}$ \\
\hline 2. & 23 Mei 2019 & $\begin{array}{l}\text { Penanganan pada masalah } \\
\text { psikososial: } \\
\text { 1. Kecemasan } \\
\text { 2. Gangguan citra tubuh } \\
\text { 3. Harga diri rendah } \\
\text { 4. Keputusasaan } \\
\text { 5. Koping tidak efektif }\end{array}$ & $\begin{array}{l}\text { Ceramah } \\
\text { Diskusi }\end{array}$ \\
\hline 3. & 24 Mei 2019 & $\begin{array}{l}\text { 1. Rujukan masalah psikososial } \\
\text { 2. Simulasi penanganan masalah } \\
\text { psikososial }\end{array}$ & $\begin{array}{l}\text { Ceramah, diskusi } \\
\text { dan simulasi }\end{array}$ \\
\hline
\end{tabular}

Kegiatan perencanaan adalah semua kegiatan yang bertujuan untuk mempersiapkan pelaksanaan program PKM dimulai dari penyusunan buku panduan kader kesehatan jiwa sekolah, jadwal pelaksanaan pembinaan dan pendampingan dan sarana prasarana yang dibutuhkan. Buku panduan kader kesehatan jiwa sekolah yang disusun berisi tentang masalah psikososial pada anak dan remaja, tindakan penanangan masalah kecemasan, harga diri rendah situasional, gangguan citra tubuh, keputusasaan, dan koping tidak efektif, dan proses rujukan.

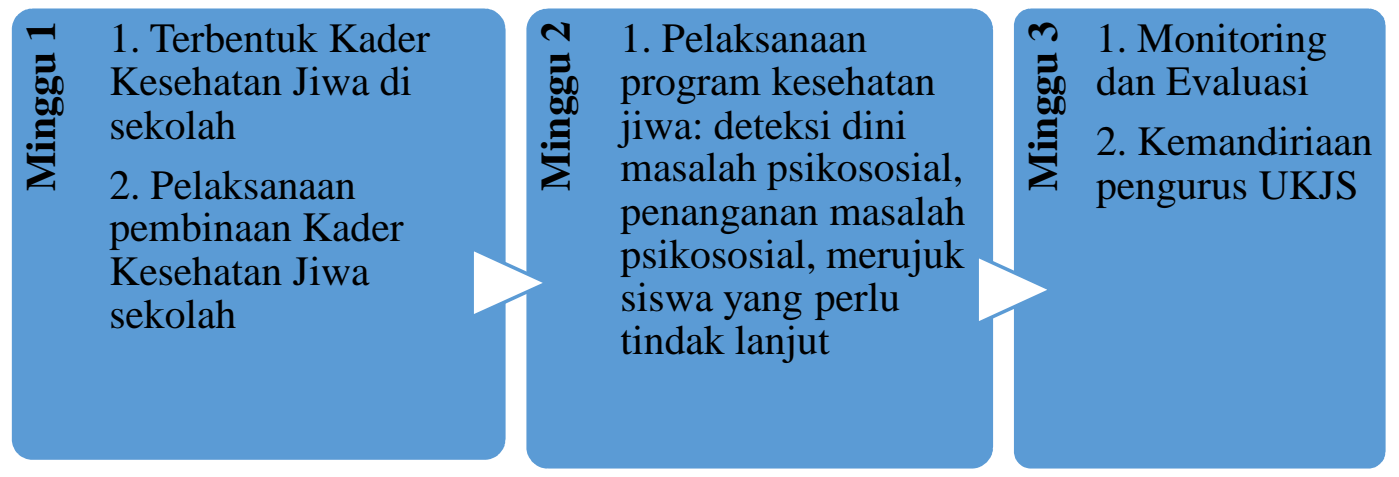

Gambar 1. Metode Pelaksananaan UKJS

Sasaran program pembentukan kader kesehatan jiwa sekolah adalah guru dan siswa. Adapun tahap-tahap pembentukan kader kesehatan jiwa sekolah adalah sebagai berikut (Widyawati, 2013 \& Ridwan, 2015) : 
1. Seleksi calon kader kesehatan jiwa dengan kriteria siswa dan guru yang terlibat aktif dalam program UKS dan PMR, sukarela, dan bersedia melakukan perannya sebagai kader kesehatan jiwa.

2. Pembuatan jadwal pelatihan, pendampingan, monitor dan evaluasi sesuai kesepakatan

3. Pelaksanaan pre test sebelum diberikan pelatihan

4. Pelaksanaan kegiatan pelatihan sebanyak 3 (tiga) kali pertemuan dengan metode ceramah, diskusi, demonstrasi dan role play.

5. Pelaksanaan post test setelah dilakukan pelatihan

6. Pelaksanaan pendampingan dalam pembuatan dan pelaksanaan program kerja kader kesehatan jiwa.

7. Pelakanaan monitoring dan evaluasi keberjalanan program kerja kader kesehatan jiwa.

\section{HASIL DAN PEMBAHASAN}

Kegiatan yang sudah direncanakan melalui beberapa tahapan yang dimulai dengan:

4.1 Pre Test Calon Kader Kesehatan Jiwa Sekolah. Model kegiatan ini dengan memberikan kesempatan kepada seluruh kader untuk mengikuti pre test yang diikuti oleh 15 siswa, kegiatan ini terlaksana pada tanggal 17 Mei 2019. Hasil ujian pre test terdapat 12 orang (80) yang memperoleh nilai dibawah 60. Foto kegiatan pre test dapat dilihat pada gambar 2 .

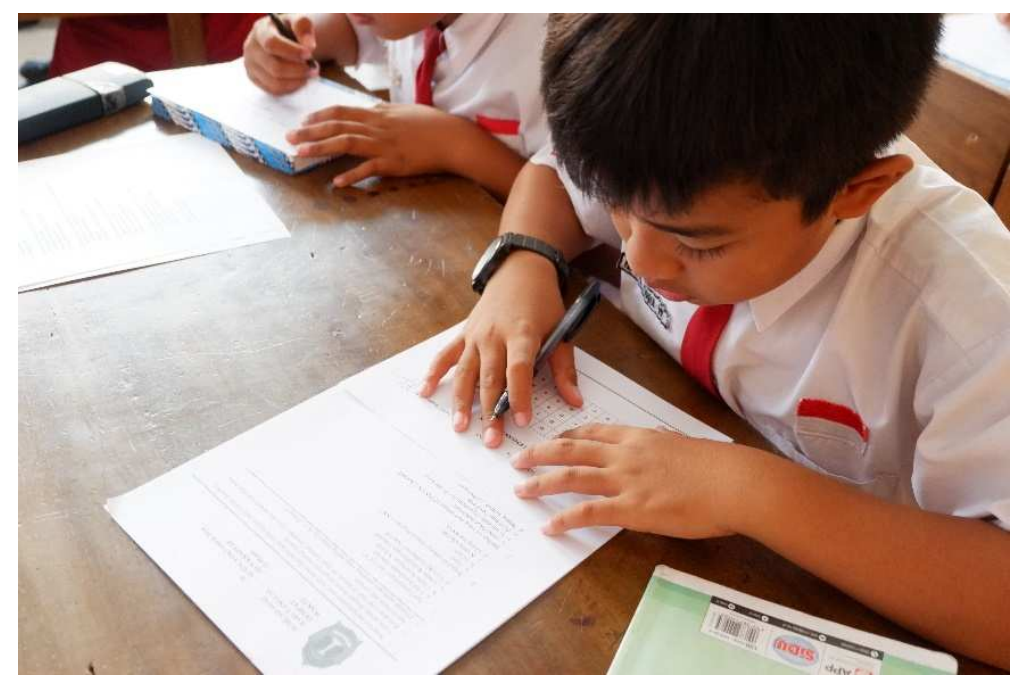

Gambar 2. Foto kegiatan Pre Test

4.2 Kegiatan pelatihan kader kesehatan jiwa yang dilaksanakan selama 3 (tiga hari) yaitu pada 22- 24 Mei 2019. Hari pertama disampaikan materi tentang konsep terjadinya masalah psikososial, macam- macam masalah psikososial pada anak: kecemasan, gangguan citra tubuh, harga diri rendah situasional, keputusasaan, dan koping tidak efektif. Kemudian, hari kedua adalah skrining masalah psikososial, penjelasan tentang konsep penanganan masalah psikososial dan rujukan. Hari ketiga 
Indonesian Journal of Community Services

Volume 2, No. 1, May 2020

http://jurnal.unissula.ac.id/index.php/ijocs

DOI: http://dx.doi.org/10.30659/ijocs.2.1.46-54

adalah simulasi penanganan masalah psikososial. Foto kegiatan pelatihan dapat dilihat pada gambar $2 \mathrm{a}$ dan $2 \mathrm{~b}$.

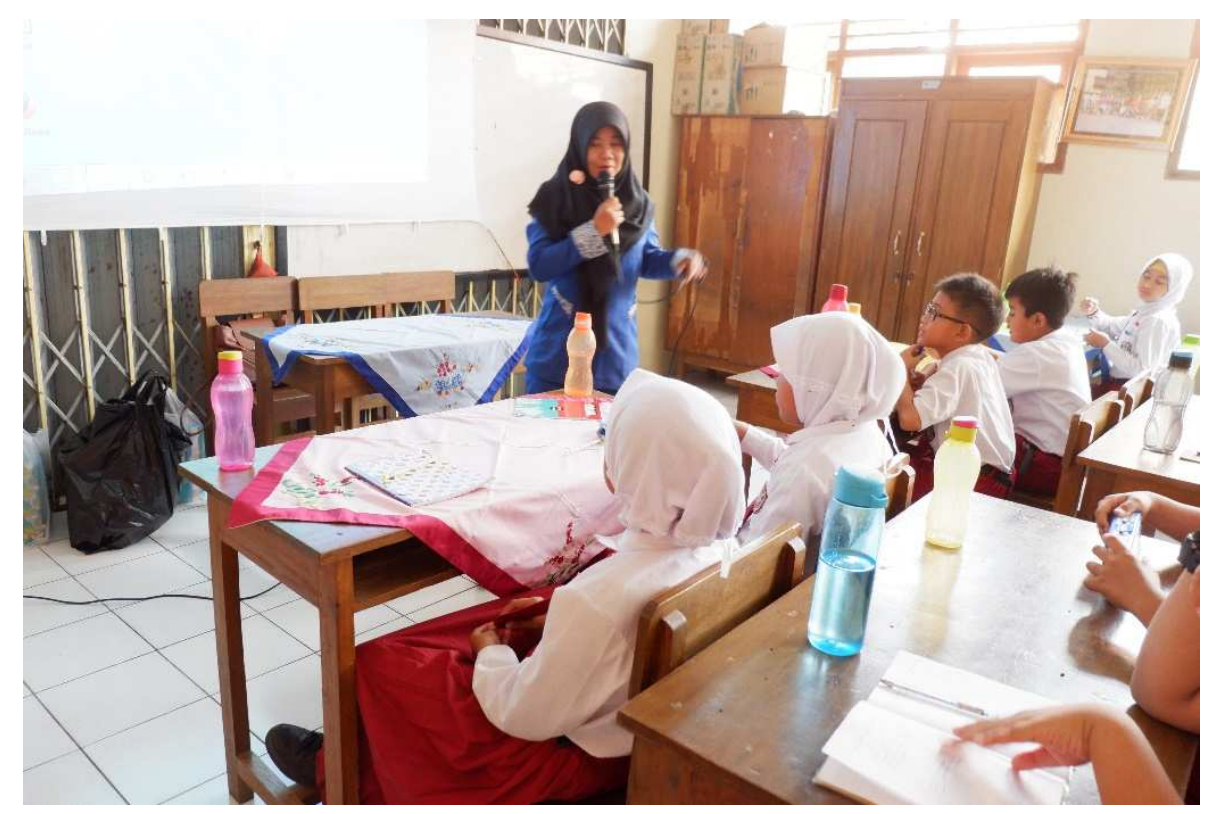

Gambar 3. Foto kegiatan pelatihan

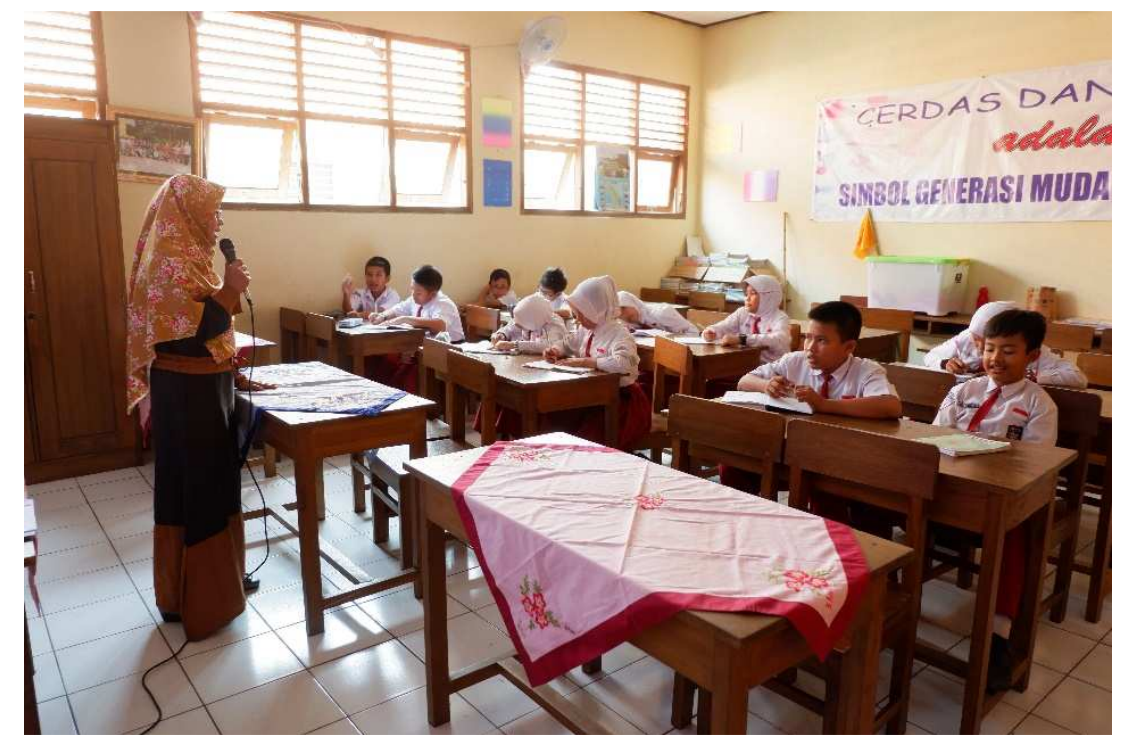

Gambar 4. Foto kegiatan pelatihan

\subsection{Post Test Kader Kesehatan Jiwa Sekolah}

Kegiatan post test bermanfaat untuk mengevaluasi pengetahuan kader kesehatan jiwa sekolah setelah mendapatkan pelatihan selama 3 hari. Hasil post test didapatkan 15 siswa (100\%) mendapatkan nilai di atas 80, artinya pengetahuan kader kesehatan jiwa sekolah meningkat menjadi baik dan sangat baik. 


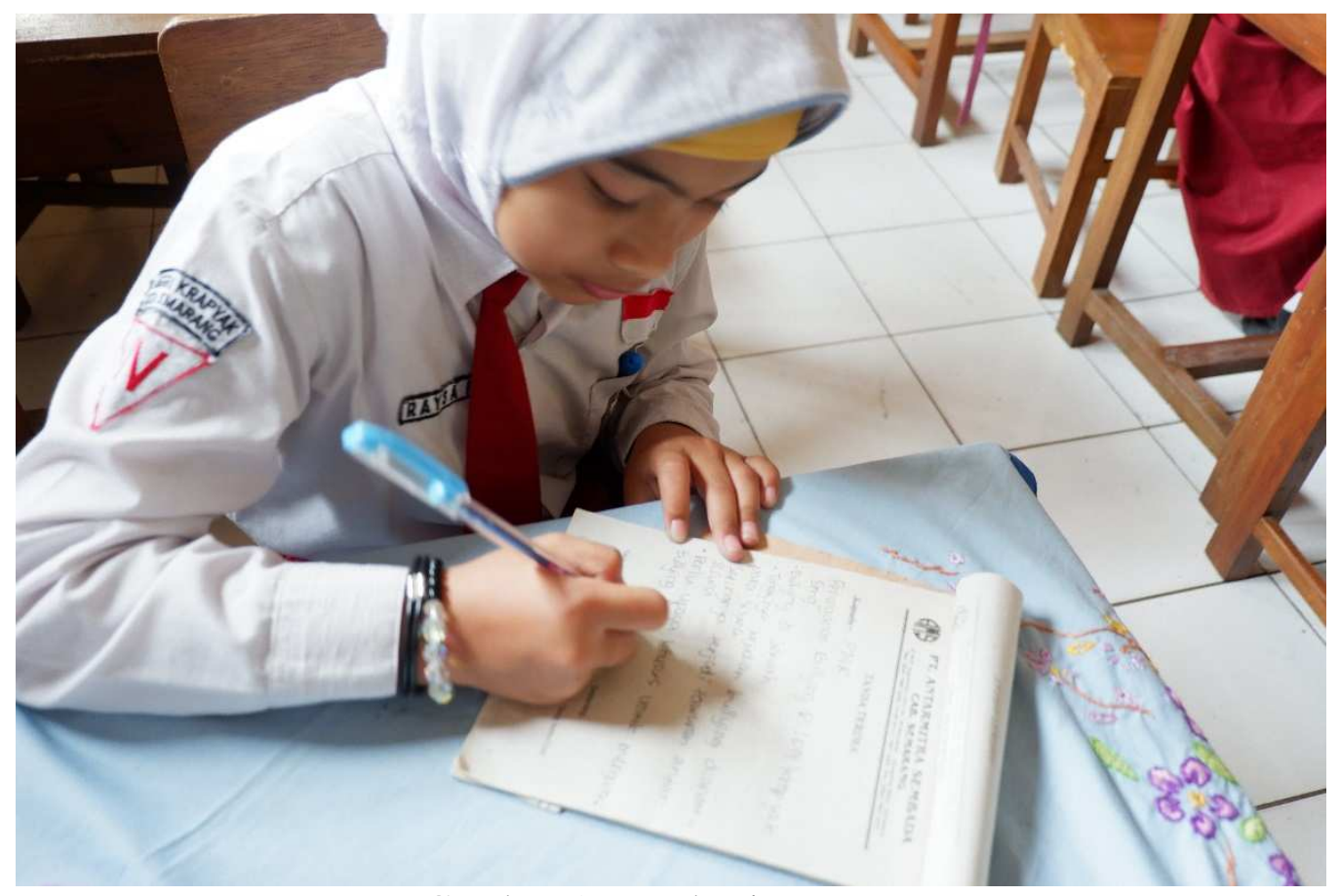

Gambar 5. Foto kegiatan Post Test

\subsection{Peer Group Conselor}

Pengembangan kelompok di kelas masing-masing tersebut merupakan cikal bakal terbentuknya peer group konselor yang secara komprehensif akan mengembangkan suatu wadah yang disebut FORDUKES (Forum Peduli Kesehatan) SD N Krapyak Semarang dengan memfasilitasi berupa menyebarluaskan materi cara penanganan masalah psikososial dengan media leaflet, power point dan lembar balik. Manfaat Kader Kesehatan Usia Sekolah dan Remaja membantu agar Anak Usia Sekolah dan Remaja dapat menolong dirinya sendiri dan orang lain untuk hidup sehat, menjadi promotor / penggerak dan motivator dalam upaya meningkatkan kesehatan diri sendiri, teman-teman dan lingkungan sekitar dan membantu teman, guru, keluarga dan masyarakat dalam memecahkan permasalahan kesehatan termasuk melakukan rujukan ke pelayanan kesehatan (Kemenristek RI, 2018).

Hubungan sebaya memiliki peranan yang kuat dalam kehidupan remaja. Hubungan sebaya menimbulkan suatu hubungan saling percaya antar teman sebaya. Hubungan ini dapat menimbulkan suatu perilaku dimana remaja lebih percaya terhadap teman sebaya daripada dengan orang tua (Sarmin, 2017).

\subsection{Monitoring dan Evaluasi}

Kegiatan yang terakhir adalah monitoring evaluasi (monev). Kegiatan monev dilaksanakan pada 26 Juli 2019. Kegiatan ini dilaksanakan dengan metode diskusi mengenai keberhasilan dan kendala selama pelaksanaan kegiatan. Hasil monev didapatkan semua siswa sudah dilakukan skrining masalah psikososial. 


\section{KESIMPULAN}

Kegiatan pengabdian masyarakat ini dapat ditarik kesimpulan bahwa:

1. Menghasilkan pembentukan kader kesehatan jiwa di Sekolah yang telah dilaksanakan di SD N Krapyak Semarang sehingga dapat diaplikasikan di tempat lain modul ini berisi tetang pembentukan dan kegiatan kader kesehatan jiwa sekolah.

2. Melatih tenaga kader kesehatan sebagai upaya keberlanjutan program yang akan dilaksnakan di SD N Krapyak Semarang melalui program UKS. Pelatihan dilakukan selama 5 kali pertemuan yang diikuti oleh 15 siswa. Kader kesehatan jiwa sekolah selanjutnya menyalurkan pengetahuannya kepada teman di lingkungan sekolah.

3. Membuat media- media penanganan masalah psikososial berupa leaflet, power point dan lembar balik yang digunakan oleh kader kesehatan jiwa sekolah untuk mencegah dan mengatasi masalah psikososial temannya di lingkungan sekolah.

\section{UCAPAN TERIMAKASIH}

Ucapan terima kasih dan penghargaan kami sampaikan kepada:

1. Pusat Penelitian dan Pengabdian Masyarakat (P3M) STIKes Widya Husada Semarang yang telah memberikan dana dalam pelaksanaan Program Pengabdian Masyarakat ini.

2. Ketua Program Studi Ners STIKes Widya Husada Semarang yang telah memberikan ijin kepada kami untuk melaksanakan kegiatan ini.

3. Kepala sekolah SD N Krapyak Semarang (Sumarni, S.Pd.SD) beserta guru dan karyawan yang telah ikut berpartisipasi aktif dalam kegiatan ini.

\section{DAFTAR PUSTAKA}

Badan Pusat Statistik. (2018). Jumlah Peserta Didik di Indonesia. https://databoks.katadata.co.id/datapublish/2019/05/02/berapa-jumlah-pesertadidik-indonesia

Keliat, dkk. (2006). Modul Basic Course Community Mental Health Nursing. Jakarta : WHO FIK UI

Keliat, dkk. (2019). Asuhan Keperawatan Jiwa. Jakarta: EGC.

Kemenristek RI. (2018). Buku KIE Kader Kesehatan Remaja. kesga.kemkes.go.id/.../Buku\%20KIE\%20Kader\%20Kesehatan\%20Remaja

Ridwan, M., Noerjoedianto, D., Amir, A. (2016). Penerapan Metode Tutor Sebaya bagi Kader Kesehatan Remaja Siswa SMA di Kota Jambi Tahun 2015. Jurnal Pengabdian pada Masyarakat Volume 31 Nomer 1 Januari- Maret . 2016. Diakses pada $\quad 14 \quad$ Agustus 2019 di https://onlinejournal.unja.ac.id/jlpm/article/view/2974/2219 
Sarmin. (2017). Konselor Sebaya: Pemberdayaan Teman Sebaya Dalam Sekolah Guna Menanggulangi Pengaruh Negatif Lingkungan. Brilliant: Jurnal Riset dan Konseptual Volume 2 Nomor 1, Februari 2017.

Stuart. Prinsip dan Praktik Keperawatan Jiwa. (2013). Singapore: Elsevier.

Wardani, Mariyati, \& Tamrin, (2019). Eksplorasi pengalaman remaja yang menjadi korban bullying di Sekolah. Jurnal Ners Widya Husada Volume 4 No. 1 tahun 2019.

Widyawati, Denny. (2013). Hubungan Peran Kader Kesehatan Jiwa dengan Tingkat Kunjungan Pasien Gangguan Jiwa di Wilayah Kerja Puskesmas Galur II Kulon Progo Yogyakarta. Diakses pada 14 Agustus 2019 di htt2p://digilib.unisayogya.ac.id/562/1/NASKAH\%20PUBLIKASI\%20DENNY\% 20WIDYATI\%20\%28090201044\%29.pdf

Yusuf, A.H. (2015). Buku Ajar Keperawatan Jiwa. Jakarta: Salemba Medika. 